\title{
Self-inflicted nail-gun injury with cranial penetration and use of intraoperative computed tomography
}

Joseph A. Carnevale, John F. Morrison, David B. Choi, Petra M. Klinge, G. Rees Cosgrove, Adetokunbo A. Oyelese

Department of Neurosurgery, Warren Alpert Medical School of Brown University, Providence, Rhode Island 02903, USA

E-mail: Joseph A. Carnevale - joseph_carnevale@brown.edu; John F. Morrison - johnfmorrison.md@gmail.com; David B. Choi - david_choi@brown.edu; Petra M. Klinge - pklinge@lifespan.org; G. Rees Cosgrove - garth_rees_cosgrove@brown.edu; *Adetokunbo A. Oyelese - aoyelese@lifespan.org

*Corresponding author

Received:01 February 16 Accepted:09 February 16 Published:06 May 16

\begin{abstract}
Background: Management of penetrating cranial trauma remains a high acuity and imaging intense neurosurgical disorder. Imaging of vital structures, including angiography, is typically conducted to understand the proximity of vital structures in comparison to a foreign body and prepare for intraoperative complications such as hemorrhage. Preservation of function following initial injury in cases where minimal neurological deficit exists is essential.
\end{abstract}

Case Description: Here, we present a case using intraoperative computed tomography to assist in early detection and resolution of hemorrhage in the surgical management of an intact patient with self-inflicted penetrating cranial trauma.

Conclusions: This method may aid in early detection of hemorrhage and prevention of consequential neurological deterioration or emergent need for secondary surgery.

KeyWords: Brain trauma, intraoperative computed tomography, penetrating brain injury, self-harm disorder, self-inflicted injury

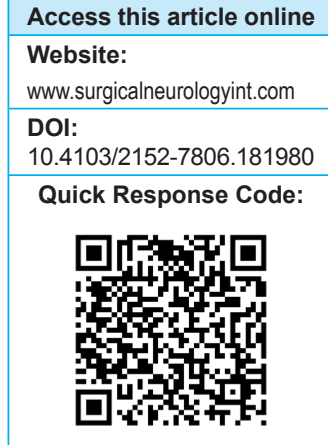

\section{INTRODUCTION}

Use of computed tomography (CT) in penetrating cranial injury has become the standard of care. This allows for localization of the path of the foreign body and indication for further imaging studies. Recently, use of intraoperative CT (IOCT) has become increasingly available in the neurosurgery armamentarium, allowing for real-time assessment of hemorrhage and noninvasive vascular studies during surgery.

Self-harm disorder is a psychiatric disorder defined as intentional, self-inflicted, injury without the intent of suicide, and covers a wide range of personal injuries such as cutting, burning, poisoning, or stabbing. ${ }^{[5]}$ Since their introduction in 1959, the increasing use of home or industrial strength pneumatic nail guns has resulted in elevated frequency self-inflicted penetrating cranial trauma from these devices. ${ }^{[3,6]}$

We describe a case wherein a patient with self-harm disorder, self-inflicts multiple nail-gun wounds including a penetrating cranial wound. This condition was operative and successfully treated with the assistance of portable IOCT allowing for both minimal cranial exposure and

This is an open access article distributed under the terms of the Creative Commons Attribution-NonCommercial-ShareAlike 3.0 License, which allows others to remix, tweak, and build upon the work non-commercially, as long as the author is credited and the new creations are licensed under the identical terms.

For reprints contact: reprints@medknow.com

How to cite this article: Carnevale JA, Morrison JF, Choi DB, Klinge PM, Cosgrove GR, Oyelese AA. Self-inflicted nail-gun injury with cranial penetration and use of intraoperative computed tomography. Surg Neurol Int 2016;7:S259-62. http://surgicalneurologyint.com/Self-inflicted-nail-gun-injury-with-cranialpenetration-and-use-of-intraoperative-computed-tomography/ 
real-time diagnostic confirmation of hemorrhage free nail extraction.

\section{CASE DESCRIPTION}

\section{History and examination}

This 60-year-old right-handed male presented to the Emergency Department following self-inflicted injuries to the head, chest, and left arm with a pneumatic powered nail gun. On presentation, he denied suicidal or homicidal ideation. He had several previous demonstration of self-injury, including a table saw injury with distal amputation of left index finger. On presentation, he had a Glasgow Coma Scale (GCS) of 15, several puncture wounds throughout the face and head, and full motor and sensation throughout upper and lower extremities. CT of the brain at admission was consistent with five large nails projected over the face and calvarium [Figure la], with one nail extending through the right temporal bone, right temporal lobe, right basal ganglia, right and left lateral ventricles, and terminating in the left basal ganglia [Figure lb]. There was a small associated right temporal subarachnoid hemorrhage but no intraventricular hemorrhage, midline shift, or basal cistern hemorrhage [Figure lb].

\section{Operative technique}

The facial and chest subcutaneous nails were removed at the bedside with sterile technique under local anesthesia. We elected to remove the intracranial nail in the operating room (OR), under general anesthesia, to allow for a controlled, sterile, environment, and possible conversion to craniotomy should hemorrhage occur. A right temporal approach was used with intraoperative 32-slice BodyTom CT (Neurologica, Danvers, MA, USA) imaging. The BodyTom is a portable, full-bore CT-imaging device that can be utilized in any OR. Use of portable intraoperative imaging was chosen for convenience and patient safety, allowing for pre- and post-removal imaging in the operating theater while the patient and instruments remained sterile as well as real-time three-dimensional imaging reconstruction [Figure 2a]. The right pterional region was carefully prepped and draped, and an IOCT scan performed to demonstrate that no new hemorrhage had occurred since initial presentation [Figure 2b]. The skin was opened in a curvilinear fashion above the temporal muscle behind the entry point of the nail and the fascia and the temporalis muscle split. The temporal bone surrounding the nail was drilled with a high-speed air drill and craniotomy extended with various size Kerrison bone punches [Figure 3a]. When freed from the surrounding bone, careful longitudinal pressure perpendicular to the skull was applied to the nail head with a Kocher clamp [Figure $3 \mathrm{~b}$ and c]. Following complete nail removal, small arterial bleeding was irrigated and coagulated and the craniotomy window/

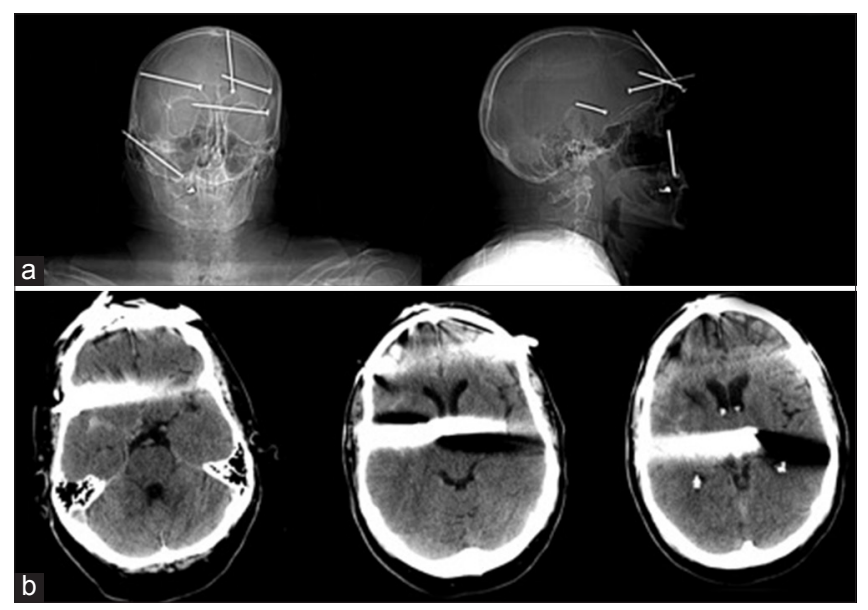

Figure I: Computed tomographic examination of the brain. (a) Scout views, anterior/posterior and lateral with multiple cranial nails. (b) Axial computed tomography views upon initial presentation consistent with a right temporal penetrating wound extending through the right and left lateral ventricles to the left basal ganglia with streak artifact from metal within the missile
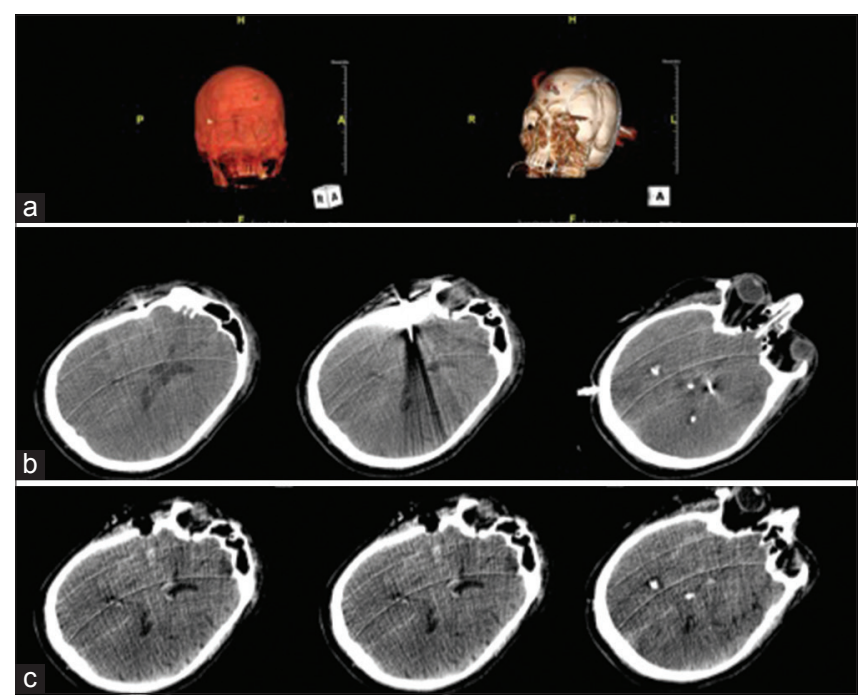

Figure 2: Intraoperative computed tomography images.(a)Top, before removing the nail. (b) Middle, three-dimensional reconstructions (c) bottom, following removing the nail demonstrating no large tract hemorrhage

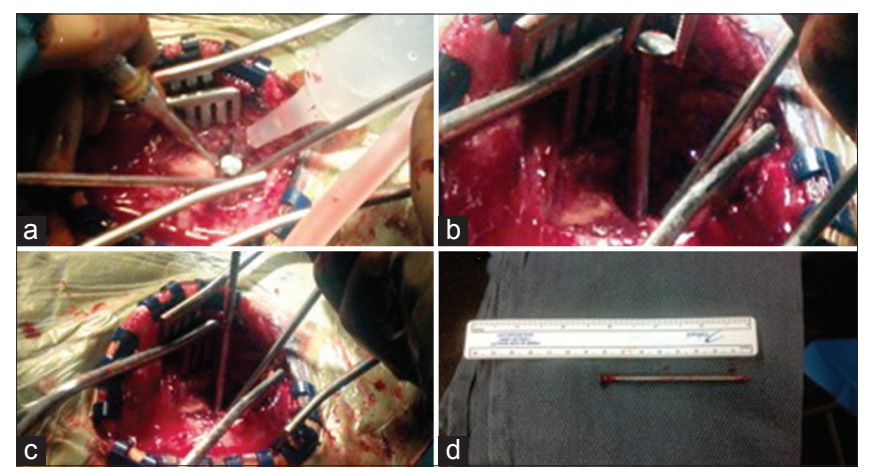

Figure 3: Intraoperative views. (a) High speed air drill around the head of the nail (b) Kocher clamp on nail head applying longitudinal force to remove nail (c) entire nail removal and inspection of associated dura and parenchyma (d) nail with reference 
dural opening slightly extended for further visualization [Figure 3c]. Subsequent repeat IOCT was performed, and a small tract hemorrhage where the nail had previously been located was visualized. However, no major vascular injury or hemorrhage was evident [Figure 2c]. The nail was $8 \mathrm{~cm}$ in total [Figures $2 \mathrm{~b}$ and $3 \mathrm{~d}$ ]. The brain was observed to be slack, and no further hemorrhage was visualize. Thereafter, the temporalis was reapproximated with 0 vicryl, the galea with 3-0 vicryl, and the skin with a running, locked 3-0 nylon suture.

\section{Postoperative course}

Following the neurosurgical procedure, the patient directly underwent removal of the left humerus nail. Thereafter, he returned to the Neurosusrgery Intensive Care Unit. Infectious disease evaluation was requested for low velocity penetrating cranial injury. Vancomycin, cefepime, and metronidazole were initiated for broad spectrum antibiotic coverage. The patient remained GCS 15 , ambulatory, and medically stable and was discharged to an inpatient psychiatry unit on postoperative day 3. Postoperative angiogram was deferred to follow-up. However, the patient was subsequently lost to follow-up.

\section{DISCUSSION}

These results suggest that further use of IOCT in penetrating cranial injury could provide useful diagnostic information that may mitigate the need for further procedures due to unseen intraoperative complications. IOCT allows for real-time visualization of acute changes in intracranial processes which are not necessarily evident from surface anatomy in surgical cases with limited exposure.

Removal of low velocity penetrating cranial missiles typically is undertaken either under local anesthesia at bedside or in the OR via craniotomy. ${ }^{[7-9]}$ The benefit of the wakened removal is an evaluation of acute neurological decline secondary to removal caused by hemorrhage. ${ }^{[8]}$ The drawback of bedside, or wakened, removal is decreased control as the patient may move unexpectedly. Typically, a decline in mental status following wakened foreign body removal results in conversion to craniotomy. While this procedure can be conducted in the OR, delay to the OR can be problematic if conducted at the bedside. Removal via intraoperative craniotomy under general anesthesia is often conducted, but changes in the neurological examination are unable to be assessed. When frank hemorrhage is not initially seen, an early postoperative examination or image is typically undertaken. Emergence from anesthesia or transportation to imaging adds further hurdles to clot evacuation should hemorrhage occur: Re-intubation or return to OR and/ or re-prepping, draping for the procedure. Here, we ameliorate both the risk of wake patient interference with a delicate deep parenchymal foreign body extraction as well as evaluate for immediate postoperative hemorrhage with IOCT while the surgical site and instrumentation is sterile for immediate intervention.

Perioperative imaging has long been used in both penetrating and nonpenetrating brain injury. Studies are undertaken immediately postoperatively to rule out intraoperative hemorrhage, at the interval with mental status changes, or to evaluate for posttraumatic pseudoaneurysm. ${ }^{[1,4,8]}$ Some advocate use of fluoroscopy, and the "road map" feature, to ensure axial trajectory during foreign body removal. ${ }^{[2]}$ In our study, the penetrating body did not appear to abut vessels, so the risk of pseudoaneurysm is negated. Likewise, use of IOCT immediately following extraction allows for evaluation of hemorrhage and fluoroscopy unnecessary. The use of portable CT allows for the patient to remain situated, sterile, on the operative table as opposed to having to be transported for imaging or outlay the cost for a dedicated operative suite equipped with a CT scanner. In our particular case, the use of IOCT-angiography though possible was unnecessary due to the lack of hemorrhage on IOCT.

Dedicated operative suites for intraoperative magnetic resonance imaging or CT have been created for procedures augmented by these imaging modalities. These facilities, however, require a dedicated space and significant capital outlay. ${ }^{[10-12]}$ Here, we utilize portable CT technology, intraoperatively, with no increase in hospital infrastructure and little or no increase in operative time. Likewise, the machine can be moved to multiple ORs, allowing for the ability to schedule concomitant cases requiring IOCT without the prerequisite infrastructure.

This study represents not only the first report of use of IOCT in penetrating cranial injury but also the first use of portable IOCT for acute brain pathology. It supports the use of IOCT in patients with penetrating cranial injuries to allow for early identification of surgical complications and minimal cranial exposure and parenchymal manipulation. This portends to decreased hospital stay and ultimately, better outcome and warrants further investigation.

Financial support and sponsorship

Nil.

Conflicts of interest

There are no conflicts of interest.

\section{REFERENCES}

I. Blankenship BA, Baxter AB, McKahn GM 2 nd. Delayed cerebral artery pseudoaneurysm after nail gun injury. AJR Am J Roentgenol 1999; $172: 54 \mid-2$. 
2. Braca J, Whapham J, Prabhu V. E-035 Ghost image extraction technique utilizing intraoperative angiography for the controlled removal of an intracranial nail. J Neurolnterv Surg 20I2;4 Suppl I:A60-I.

3. Edlich RF, Silloway KA, Rodeheaver GT, Morgan RF, Birk K, Thacker JG. Industrial nail gun injuries. Compr Ther 1986;12:42-6.

4. Englot DJ, Laurans MS, Abbed K, Bulsara KR. Removal of nail penetrating the basilar artery. Neurosurg Rev 2010;33:50I-4.

5. Herpertz S. Self-injurious behaviour. Psychopathological and nosological characteristics in subtypes of self-injurers. Acta Psychiatr Scand 1995;91:57-68.

6. McCorkell SJ, Harley JD, Cummings D. Nail-gun injuries. Accident, homicide, or suicide? Am J Forensic Med Pathol 1986;7:192-5.

7. Musa BS, Simpson BA, Hatfield RH. Recurrent self-inflicted craniocerebral injury: Case report and review of the literature. Br J Neurosurg 1997; I I:564-9.
8. Sakuta $Y$, Arai S. Penetrating brain injury and traumatic aneurysm caused by a nail gun. No Shinkei Geka 1997;25:357-62.

9. Salar G, Costella GB, Mottaran R, Mattana M, Gazzola L, Munari M. Multiple craniocerebral injuries from penetrating nails. Case illustration. J Neurosurg 2004; 100:963.

10. Sutherland GR, Louw DF. Intraoperative MRI: A moving magnet. CMAJ |999; |6I:1293.

II. Tormenti MJ, Kostov DB, Gardner PA, Kanter AS, Spiro RM, Okonkwo DO. Intraoperative computed tomography image-guided navigation for posterior thoracolumbar spinal instrumentation in spinal deformity surgery. Neurosurg Focus 2010;28:EII.

12. Uhl E, Zausinger S, Morhard D, Heigl T, Scheder B, Rachinger W, et al. Intraoperative computed tomography with integrated navigation system in a multidisciplinary operating suite. Neurosurgery 2009;64 5 Suppl 2:23 I-9. 